\title{
Analysis of the methods for projection of spaces for good manufacturing practice
}

\author{
Elena Panovski-Nikoljski ${ }^{1}$, Aleksandar Petanovski², Ivo Spiroski ${ }^{*}$
}

${ }^{1}$ Faculty of Design and Technology of furniture and interior, Ss Cyril and Methodius University of Skopje, Skopje, Republic of Macedonia; ${ }^{2}$ Faculty of Architecture, Ss Cyril and Methodius University of Skopje, Skopje, Republic of Macedonia; ${ }^{3}$ ID Design 2012/DOOEL Skopje, Skopje, Republic of Macedonia

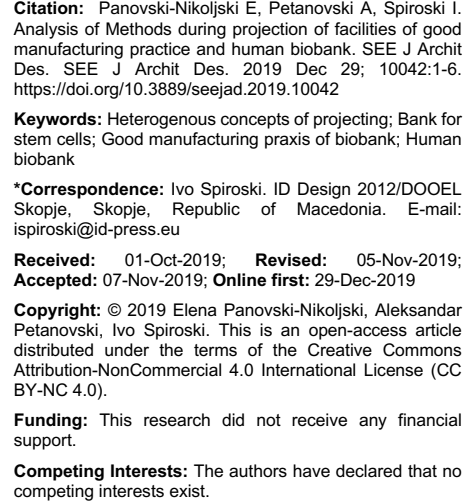
Analysis of Methods during projection of facilities of good manufacturing practice and human biobank. SEE J Archt Des. SEE J Archit Des. 2019 Dec 29; 10042:16. Keywords: Heterogenous concepts of projecting; Bank for stem cells; Good manufacturing praxis of biobank; Human

*Correspondence: Ivo Spiroski. ID Design 2012/DOOEL Skopje, Skopje, Republic of Macedonia. E-mail ispiroski@id-press.eu

Received: 01-Oct-2019; Revised: 05-Nov-2019; Accepted: 07-Nov-2019; Online first: 29-Dec-2019

Copyright: ๑ 2019 Elena Panovski-Nikoljski, Aleksandar Petanovski, Ivo Spiroski. This is an open-access article Atrribution-NonCommercial 40 international License (CC BY-NC 4.0).

Funding: This research did not receive any financial support.

Competing Interests: The authors have declared that no competing interests exis.

\begin{abstract}
BACKGROUND: In this Paper we will present the evolution of the best practice for biobanks, the technical and medical standards for collecting, processing and storing, as well as the socio-economic standards for biobank management.

AIM: The aim of this Thesis is to analyse and to present the methods for projection of spaces for good manufacturing practice.

METHODS: The European Union has adopted guidelines for good manufacturing practice which define the requirements for manufacturing of sterile products. In the following text we will describe the details for determining microbiological cleanliness and cleanliness of the particles in the air, on the surfaces, etc.

RESULTS: The length of time between the collecting of blood or tissues could affect the final result. The preparation of sterile products requires special conditions, in order the risk of microbiological contamination and certain pyrogenic contaminations to be minimized. We make difference between four levels of guidelines for good manufacturing practice, which in this Paper are taken from the practice of the European Union. Level A is local zone with high-risk procedures, e.g. filling, closing of bottles, opening of ampoules and bottles and making septic connections. Level $B$ is aseptic preparation and filling of the samples. Level C and D are the clean spaces for less critical procedures for preparation of sterile products.
\end{abstract}

CONCLUSION: Technical standards, medical standards, socio-economic standards for biobank management, informatics practices for biobanks, economic recommendations for biobanks have been established, as well as a quality of biobanks has been provided.

\section{Introduction}

Every year millions of biological samples are collected for different purposes, including main scientific investigations, clinical studies and epidemiological studies [1]. The biological samples are stored in biobanks, which could be also called biostores (biorepositories), resources for biological samples or centres for biological samples, which are used for further analyses. In the clinical laboratory the storing of blood and urine from patients is base for a number of examinations and analyses [2]. For making diagnosis, as well as for scientific investigations, are collected frozen tissues or formalin fixed tissues in clinical conditions [3]. Many years ago, the standard operative procedures, the reference standards and the quality control were the main requirements for the clinical laboratories. For clinical investigations were determined precise rules, whereas for the biological samples collected for scientific investigations they were not so precise.

The first banks for stem cells and the most frequent in the world are the banks for stem cells from the umbilical cord. In the world have been developed banks for stem cells for family use and public available banks for stem cells.

The banks for stem cells for family use are private banks, where one family is storing blood from the umbilical cord or isolated stem cells, which could be potentially used for some of the close members of the 
family.

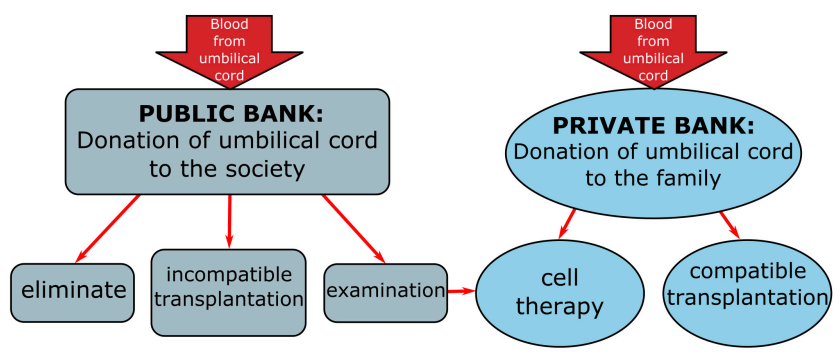

Figure 1: Donating blood from the umbilical cord in public and private bank

Public available banks are funded by state institutions or by foundations, where married couples by signed consent are donating the blood from the umbilical cord, from which the stem cells are isolated and stored and they are used for any patient, if this patient is genetically identical.

In rare cases the samples from the stored stem cells of the family from the family banks for stem cells later could be donated to the public banks for stem cells and to be used for patients beyond their family. Generally this is done with adequate material compensation. Because the family is paying for the storing of the stem cells and in the public banks the patients are not paying for it, but the costs are borne by the country.

In the recent years a number of organisations have evolved and published numerous best practices which regulate the principles for storing biological samples [4]. These documents cover the technical aspects of the biological samples, as collecting, processing, storing, providing quality, information systems for data collection, as well as ethical and regulatory issues, e.g. the informed consent, the privacy of the patients and the intellectual property.

\section{Results}

\section{Technical standards}

The technical best practices include recommendations for "the bases" of the biobanks: collecting, processing, storing and distribution of biological samples, as well as the relevant data from the collections and its management. Recently, a new field in the science for biological samples has been presented, which tries to develop the best practices based on evidences and standard operative procedures [5]. Since the investigation of biological samples has been developed as a specific field, everything became more visible within the development of the best practices, based on the evidences from the literature. For example, evidences have been collected that the length of the time between the collection of blood or tissues could affect the final result [6]. Multiple defrosting and freezing of the blood samples, could also negatively affect on certain analytical procedures, although for nucleic acids, some hormones and microelements, these effects are minimal [7].

\section{Medical standards for collecting, processing and storing}

Examples of variables which should be taken into consideration:

- collecting blood - test tubes for collecting which contain etylenediaminetetraacetic acid (EDTA) or heparin, may affect the analysis [8].

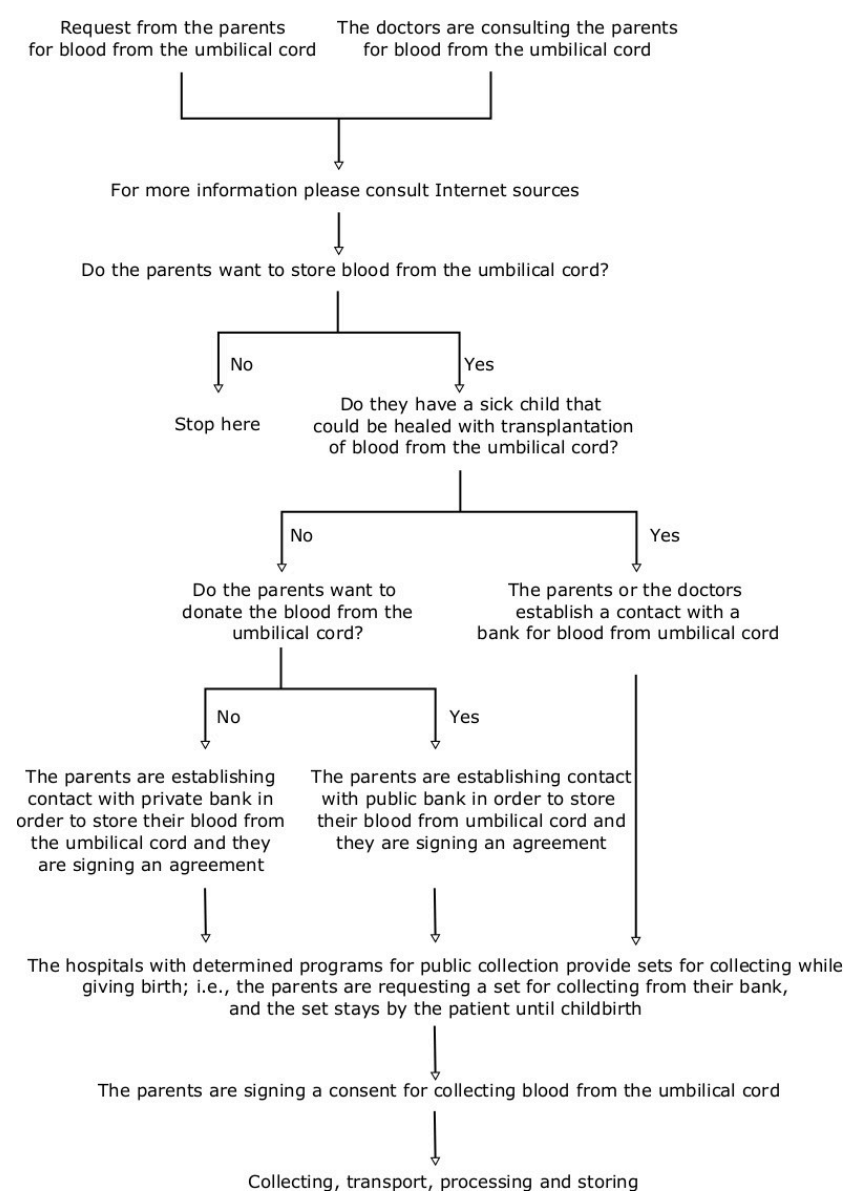

Figure 2: Succession of procedures for taking blood from the umbilical cord

- storing - for long-term storing of live cells in liquid nitrogen, crucial is the temperature. Other samples, as for example DNA or plasma, in most cases are instable if they are stored at $-80^{\circ} \mathrm{C}$ in freezers or at higher temperatures [9].

- processing - the duration of fixing with formalin could affect the later analyses [10].

These and other significant recommendations are included in all documents for best practice of 
biological samples. Most general recommendations are given in the documents of the International Society for Biological and Environmental Repositories (ISBER) [11] and taken from the practices of the Nacional Cancer Institute (NCI) [12]. Subsequently, the best practices should be consulted by the biobanks located in different places in the world, where the recommendations could be adjusted for the local needs and use [13].

\section{Socio - economic standards for biobanks management}

Smaller biobanks, which are part of greater programms or institutions should not have managing structure, except if they are existing as greater organisations. Although, the managing and the operative structures are important for great academic, governmental and commercial biobanks. These practices usually include managing and plan for the employees, roles and responsibilities of all employees, external committees that give advices for the scientific initiatives and apply the policy of biological samples, business planning and covering of costs, planning and using, as well as equipment and materials, necessery for the work [14].

\section{Informatics practices for biobanks}

The information science in biobanks is covering some critical areas: following of biological samples, collecting of samples (clinical, quality of samples, demography) and identification of elements needed for each investigation, data security and privacy protection, as well as interoperability of the systems [15]. Interoperability of information science of the biobanks enables data exchange within biobanks which are functioning as part of one network. Some other informatics problems for biobanks, are:

- Which type of finding, following, collecting of data and analysis of data would be necessary?

- If these needs could be fulfilled by the existent institutional systems or an introduction of new commercial systems would be needed?

- If the collecting and the exchange of systems would be compatible in the biobank? Would it be necessary a new web interface for data collection to be created?

The best practices for informatics in biobanks include recommendations for resolving these issues, when new biobank or development of network of biobanks is planned to be established.

\section{Economic recommendations for biobanks}

A lot of biobanks are developed with a little knowledge of the good business practices or through covering of costs by the institutions and scientists that are using the biological samples. Though, the economic recommendations began to be included in the best practices, including those of $\mathrm{NCl}$ [16], because substantial financial means are needed for collecting, processing and storing of large collections. These recommendations include adjusting the standard business practices, in order all costs connected to establishing and maintaining the biobanks, to be understood. These costs include employees, equipment and its maintenance, maintaining quality and information science for data collection. When we will understand well all these costs, the fully or partial covering of the costs could provide long term sustainability of biobanks and discourage the requests for huge number of samples [17]. For a lot of examinations is the money refund not adequate, because the price for collecting biological samples is included in the projects or in the contracts for supporting the examination.

\section{Providing quality of the spaces for good manufacturing practice}

One of the main issues connected to the best practice of biobanks is the plan for quality management, which consists of providing quality and quality control. The definitions for providing quality and control of quality of biobanks are similar to that of the laboratories and other organisations which have that kind of plans for following the activities [18]. As shown in the best practice of $\mathrm{NCl}$, an effective system for quality management requires:

- Maintenance of the equipment and protocols for repair and following;

- Training and observing the work recommendations by the employees;

- Plan for data management;

- Formal following procedure;

- Development and observing the standard operative processes (SOP);

Special nature of biobanks requires instructions for standard operative procedures, which describe the following policies and procedures:

1. handling of biological samples;

2. laboratory procedures; materials

3. protocols for sending and receiving of

4. contracts for transfer;

5. system for records management;

6. security of the building, the personnel and the biological samples; 
7. waste safety and waste disposal;

8. procedures for reviewing documents and reports for injuries of employees and exposures to danger;

9. maintaining the equipment, repair and marking the calibrations;

These policies and procedures should be used for writing a plan for quality control, which would help the external controllers of biobanks and their managerial structures to examine the compliance with SOP [19].

\section{Specifics for projection of spaces for good manufacturing practice}

Use of clean room [20]

There are many standards for using a clean room, depending on its use. Generally, clean rooms are constructed for manufacturing of processors in the industrial informatics, manufacturing of sterile pharmaceutical preparations, for preparing of stem cells, as well as for other similar procedures. For all the types of clean rooms are prescribed standards for their construction, equipping and functioning, and in this case will be used the European recommendations for good manufacturing practice of medical products for human and animal use [21].

Principle: The preparation of sterile products requires special conditions in order the risk of microbiological contamination and certain pirogenic contaminations to be minimized. It depends the most from the experience, training and the conduct of the personnel included. Quality assurance is especially important and this type of production must strictly follow the carefully determined and confirmed methods for preparation and procedure. The final sterilization or the other aspects of quality must be part of each final or complete product.

General remarks: 1. Creation of sterile products should be done in rooms with clean air, where the air from the personnel, the equipment and the materials is strictly controlled. Clean rooms should be maintained with certain cleanliness and be provided with air, which passes through filters with certain efficacy; 2. Various procedures for preparation of the products, as well as the filling should be done in special parts of the clean area. The creation of products is divided into two categories - first, the category where the product is terminally sterilized and second, the category where the product is processed aseptically, for some or for all rates; and 3. Clean rooms for production of sterile products are classified according to the characteristics of the environment needed. Each production operation requires relevant level of cleanliness of the environment in operative condition, in order the risk of particles or microbial contamination of the product or the created materials to be minimized.

For "operative" conditions to be achieved, these areas should be designed for achieving certain level of air cleanliness „at standstill". "Standstill" is condition when the installations are installed and are completely functioning with the equipment, but the personnel is not present. "Operative" condition is condition when the installations are functioning in the defined operative way with certain number of working personnel.

The conditions „at standstill“ and "operativity“ sholud be defined for each clean room and to corespond to the conditions for clean room [22]:

a) „at standstill“ or "inactivity“: when the objects and systems are fully installed and are working, but in absence of operators;

b) "operative" or "activity": when the objects and systems are in working mode, with presence of operators.

For production of sterile medical products, we make a difference of 4 levels (Table 1 ).

Table 1: Number of maximum allowable particles in $\mathrm{m}^{3}$ in the rooms at standstill and during operation, for preparation of sterile solutions

\begin{tabular}{ccccc}
\hline \multicolumn{5}{c}{$\begin{array}{c}\text { Number of maximum allowable particles in } \mathbf{~ m}^{\mathbf{3}} \\
\text { tabular number }\end{array}$} \\
\hline \multicolumn{7}{c}{ equal to or bigger than the } \\
\hline Level & $\mathbf{0 , 5} \boldsymbol{\mu m}$ & $\mathbf{5 , 0} \boldsymbol{\mu m}$ & $\mathbf{0 , 5} \boldsymbol{\mu m}$ & During operation \\
A & 3520 & 20 & 3520 & $\mathbf{5 , 0} \boldsymbol{\mu m}$ \\
B & 3520 & 29 & 352000 & 20 \\
C & 352000 & 2900 & 3520000 & 2900 \\
D & 3520000 & 29000 & Nondefined & Nondefined \\
\hline
\end{tabular}

Level A: local zone with high risk procedures, e.g. zones for filling, closing of bottles, opening of ampoules and bottles, making aseptic connections. These ingredients are provided by equipment with laminar air flow. The systems for laminar air flow should provide homogeneous speed of the air, ranging from 0,36 to $0,54 \mathrm{~m} / \mathrm{s}$ (recommended values) in the working area, from the rooms with open working space. Maintaining of laminarity should be shown and validated. One direction air flow and lower speeds could be used in closed isolators and boxes, with hand gloves.

Level B: for aseptic preparation and filling an environment with Level $A$ is needed.

Level C and D: clean rooms for conducting less critical procedures during preparation of sterile products.

Clean rooms and the equipment for clean air may be classified according to the standard EN ISO 14644-1. The number of maximum allowable particles in the air is given in Table 1.

\section{Classification of clean rooms}

Clean rooms and the equipment for clean air 
should be classified according to EN ISO 14644-1 [23]. The classification should be clearly differed from the conditions for following the operative process. The maximum allowable concentration of air particles for each level should be given in Table 1.

Table 1: Number of maximum allowable particles in $\mathrm{m}^{3}$ in the spaces at standstill and during operation, for preparation of sterile solutions

\begin{tabular}{lcccc}
\hline & \multicolumn{3}{c}{$\begin{array}{c}\text { Number of maximum allowable particles in } \mathrm{m}^{3} \text { equal to or bigger than } \\
\text { the tabular number }\end{array}$} \\
\cline { 2 - 5 } & \multicolumn{3}{c}{ At standstill } & \multicolumn{2}{c}{ During operation } \\
\cline { 2 - 5 } & $0,5 \mu \mathrm{m}$ & $5,0 \mu \mathrm{m}$ & $0,5 \mu \mathrm{m}$ & $5,0 \mu \mathrm{m}$ \\
Level & 3520 & 20 & 3520 & 20 \\
B & 3520 & 29 & 352000 & 2900 \\
C & 352000 & 2900 & 3520000 & 29000 \\
D & 3520000 & 29000 & Nondefined & Nondefined \\
\hline
\end{tabular}

For classification of the zones from Level $A$ at least one $\mathrm{m}^{3}$ of air for each location is needed. For Level A of the classification of air particles the standard ISO 4.8 is determining a limit of the particles equal or bigger than 5,0 $\mu \mathrm{m}$. For Level B "at standstill", the classification of air particles is ISO 5 for both designated sizes of the particles. For Level C „at standstill and during operation", the classification of air particles is ISO 7 and ISO 8. For the level D ,at standstill" the classification of air particles is ISO 8. For classification according to EN ISO 14644-1, the methodology is defining minimal number for each location and size according to the limit of the class of the largest particles and the method for determining the collection of data. A mobile particle counters with short test tubes for collecting should be used, because of the relatively high precipitation level i.e. „sedimentation“ of the particles, equal of bigger than $5,0 \mu \mathrm{m}$, which happens in the remote systems for taking samples with large length of the test tube. An isokinetic sample heads, that use system of one directed passing air, should be used. The classification "during operation" may be shown during normal functioning, simulated functioning or during filling of medium, as the worst simulation needed for this standard. EN/ISO 14644-2 gives information for testing and shows continued compliance with the classification of cleanliness.

\section{Conclusions}

Based on the analysis of methods for projection of the spaces for good manufacturing practice we could come to the following conclusions:

Analysing the conditions in the developed world it is determined that there are and are developed banks for stem cells for family use and public available banks for stem cells. The banks for stem cells for family use are private banks, where the family is storing blood from the umbilical cord or isolated stem cells, which could potentially be used for one of the close members of the family. Public available banks are funded by state institutions or foundations, where married couples by signed consent are donating blood from the umbilical cord, from which stem cells are isolated and stored and subsequently used for any person, if this person is genetically identical.

The results of this Paper for analysis of the methods for projection of the spaces for good manufacturing practice would contribute for following the medical standards for collecting, processing and storing of biological samples, on behalf of the healthcare.

The conditions for production of sterile products that define the instructions for good manufacturing practice in this Paper are taken from the European practice. We make a difference between four levels of instructions for good manufacturing practice, which in this Paper is taken from the European practice. Level A is local zone with high-risk procedures, e.g. filling, closing of bottles, opening of ampoules and bottles and making septic connections. Level $B$ is aseptic preparation and filling of the samples. Level $C$ and $D$ are the clean spaces for less critical procedures for preparation of sterile products.

Technical standards, medical standards, socio-economic standards for biobank management, informatics practices for biobanks, economic recommendations for biobanks have been established, as well as the quality of biobanks has been provided.

\section{References}

1. Eiseman E, Haga SB, editors. Handbook of human tissue sources: a national resource of human tissue samples. Santa Monica, CA: RAND Corporation; 1999.

2. Riegman PH, Dinjens WN, Oosterhuis JW. Biobanking for interdisciplinary clinical research. Pathobiology. 2007; 74:239-44.

3. Hughes $\mathrm{S}$, Barnes $\mathrm{RO}$, Watson $\mathrm{PH}$. Biospecimen use in cancer research over two decades. Biopreserv Biobanking. 2010; 8:89-97.

4. Vaught J, Caboux E, Hainaut $P$. International efforts to develop biospecimen best practices. Cancer Epidemiol Biomarkers Prev. 2010; 19:912-5.

5. Moore HM, Compton CC, Alper J, Vaught JB. International approaches to advancing biospecimen science. Cancer Epidemiol Biomarkers Prev. 2011; 20:729-32.

6. Hatzis C, Sun H, Yao H, Hubbard RE, MericBernstam F, Babiera YW, et al. Perioperative ischemia and tissue preservation effects on RNA integ239rity and microarrays of breast cancer. J Natl Cancer Inst. 2011; 103:1871-83. 
7. Comstock GW, Burke AE, Norkus EP, Gordon GB, Hoffman SC, Helzlsouer KJ. Effects of repeated freeze-thaw cycles on concentrations of cholesterol, micronutrients, and hormones in human plasma and serum. Clin Chem. 2001; 47:139-42.

8. Vaught JB. Blood collection, shipment, processing and storage. Cancer Epidemiol Biomarkers Prev. 2006; 15:1582-4.

9. $\mathrm{NCl}$ Best Practices for biospecimen resources. Table of contents. http://biospecimens. cancer.gov/bestpractices/toc/2011 Accessed March 6, 2012.

10. Khoury T, Sai S, Hwang J, et al. Delay to formalin fixation effect on breast biomarkers. Mod Pathol. 2009; 22:1457-67.

11. ISBER best practices for repositories. Cell Preserv Technol. 2008; 6:1-58.

12. $\mathrm{NCl}$ Best Practices for biospecimen resources. Table of contents. http://biospecimens. cancer.gov/bestpractices/toc/2011 Accessed March 6, 2012.

13. Vaught J, Caboux E, Hainaut $P$. International efforts to develop biospecimen best practices. Cancer Epidemiol Biomarkers Prev. 2010; 19:912-5.

14. $\mathrm{NCl}$ Best Practices for biospecimen resources. Table of contents. http://biospecimens. cancer.gov/bestpractices/toc/2011 Accessed March 6, 2012.

15. $\mathrm{NCl}$ Best Practices for biospecimen resources. Table of contents. http://biospecimens. cancer.gov/bestpractices/toc/2011 Accessed March 6, 2012.

16. Vaught J, Rogers J, Carolin T, Compton C. Biobankonomics: developing a sustainable business model approach for the formation of a national cancer human biobank by the National Cancer Institute. JNCI Monogr. 2011; 42:24-31.

17. Vaught J, Rogers J, Carolin T, Compton C. Biobankonomics: developing a sustainable business model approach for the formation of a national cancer human biobank by the National Cancer Institute. JNCI Monogr. 2011; 42:24-31.

18. Centers for Disease Control and Prevention laboratory quality assurance and standardization program. http://www.cdc.gov/labstandards/ Accessed March 9, 2012.

19. Master Control web site. http://www.mastercontrol.com/document-controlsoftware/ Accessed March 9, 2012.

20. Centers for Disease Control and Prevention laboratory quality assurance and standardization program. http://www.cdc.gov/labstandards/ Accessed March 9, 2012.

21. EudraLex. The Rules Governing Medicinal Products in the European Union. Volume 4. EU Guidelines to Good Manufacturing Medicinal Products for Human and Veterinary Use. EUROPEAN COMMISSION ENTERPRISE AND INDUSTRY DIRECTORATE-GENERAL: Brussels, 25 November 2008.

22. EudraLex. The Rules Governing Medicinal Products in the European Union. Volume 4. EU Guidelines to Good Manufacturing Medicinal Products for Human and Veterinary Use. EUROPEAN COMMISSION ENTERPRISE AND INDUSTRY DIRECTORATE-GENERAL: Brussels, 25 November 2008.

23.

UNI-EN-ISO

$14644-1 / 2 / 3 / 4 / 5 / 7$ 